\section{Atividade de cárie na dentição decídua, Indaiatuba, São Paulo, Brasil, 2004}

\author{
Dental caries activity in primary dentition, \\ Indaiatuba, São Paulo, Brazil, 2004
}

\author{
${ }^{1}$ Faculdade de Odontologia \\ de Piracicaba, Universidade \\ Estadual de Campinas, \\ Piracicaba, Brasil. \\ 2 Faculdade de Odontologia, \\ Pontifícia Universidade \\ Católica de Campinas, \\ Campinas, Brasil. \\ 3 Direção Regional de \\ Saúde de Campinas, \\ Campinas, Brasil. \\ ${ }^{4}$ Prefeitura Municipal \\ de Indaiatuba, Brasil. \\ Correspondência \\ M. L. R. Sousa \\ Departamento de \\ Odontologia Social, \\ Faculdade de Odontologia \\ de Piracicaba, Universidade \\ Estadual de Campinas. \\ Av. Limeira 901, Piracicaba, SP \\ 13414-018, Brasil. \\ luzsousa@fop.unicamp.br
}

\begin{abstract}
This study aimed to verify caries activity and analyze caries experience, treatment needs, and enamel defects in 5-year-old preschool children in Indaiatuba, São Paulo State, Brazil. 624 children were selected by systematic random sampling in 2004. WHO criteria were used to measure caries experience and treatment needs. Nyvad et al. diagnostic criteria were used to analyze caries activity. Mann-Whitney and qui-square tests were used to analyze the results, with 5\% significance. $40.5 \%$ of schoolchildren displayed caries activity. The dfmt was 1.62 (95\%CI: 1.351.89). Among children with dfmt $>0$, the index was 3.81 (95\%CI: 3.36-4.26), and 91.4\% of these children presented caries activity. Care Index was $12.3 \%$. These results suggest that treatment measures and health promotion should continue to be prioritized, since the control measures and caries interruption during the initial stages are well known. Dental care should especially target schoolchildren with more significant caries experience.
\end{abstract}

Dental Caries; Dental Fluorosis; Oral Health; Preschool Child

\author{
Lilian Berta Rihs 1 \\ Maria da Luz Rosário de Sousa ${ }^{1}$ \\ Silvia Cypriano 2 \\ Nádja Moscoso Abdalla 3 \\ Danielle Duo Ngatsuka Guidini 4 \\ Carolina Amgarten 4
}

\section{Introdução}

Estudar a saúde bucal em crianças de até cinco anos de idade torna-se importante devido ao fato da experiência de cáries na dentição decídua ser considerada como o mais forte preditor da doença na dentição permanente 1,2,3. Em estudo longitudinal, Skeie et al. ${ }^{3}$ verificaram que apresentar duas superfícies dentárias cariadas aos cinco anos de idade foi um preditor clínico de alta experiência de cárie aos dez anos de idade.

Estudos direcionados à dentição decídua não têm relatado o mesmo declínio na prevalência de cáries que vem sendo verificado na dentição permanente ${ }^{4}$, além de mencionarem um aumento na média ceod, com elevadas proporções de cáries não tratadas aos cinco anos de idade 5,6,7,8

Ressalta-se que a verificação da atividade de cárie em levantamentos epidemiológicos tornase cada vez mais importante, uma vez que através do diagnóstico precoce das lesões iniciais de cárie, ainda em estágio reversível, e a avaliação de fatores determinantes auxiliam na avaliação de risco de cárie e tornam o tratamento mais simples, menos invasivo e de menor custo, envolvendo uso de flúor e mudanças de comportamento com relação à dieta e à higiene bucal 9 . Dessa forma, muitos municípios que apresentam índices de cárie controlados (medidos pelo ceod ou CPOD) poderiam utilizar os dados referentes à atividade de cárie visando a direcionar 
os serviços odontológicos para essa população, interrompendo a história natural da doença.

No entanto, a maioria dos serviços tem dado ênfase ao tratamento odontológico às crianças em idade escolar, priorizando o atendimento na fase de irrompimento dos primeiros molares permanentes 4,10 , deixando de lado o que poderia ser priorizado, ou seja, interpor barreiras à história natural da doença com medidas de prevenção e promoção de saúde o mais precocemente possível, como foi verificado em um estudo ecológico realizado no Estado de Minas Gerais, Brasil, onde foram verificados 65 municípios. Desses, apenas $9,2 \%$ tinham atingido as metas para o ano 2000 propostas pela Organização Mundial da Saúde (OMS) para a idade de cinco anos; já aos 12 anos de idade, $37 \%$ dos municípios tinham alcançado a meta da OMS para esta idade ${ }^{4}$.

Assim, este trabalho teve como objetivos avaliar a atividade de cárie na dentição decídua, além disto, verificar a prevalência de cárie (através do índice ceod), necessidades de tratamento e prevalência de defeitos de esmalte em pré-escolares de cinco anos de idade do Município de Indaiatuba, no ano de 2004.

\section{Material e métodos}

O Município de Indaiatuba está localizado a $112 \mathrm{~km}$ de São Paulo, na região sudoeste do estado e possui 160 mil habitantes. Apresenta águas de abastecimento público fluoretadas desde 1979 e atualmente, $94,4 \%$ das residências são favorecidas com abastecimento de água. O Índice de Desenvolvimento Humano (IDH) no município em 2000 foi de 0,83 , maior que a média geral do estado para o mesmo ano, que foi de 0,81 11 .

Para o cálculo do tamanho da amostra utilizou-se o valor da média ceod ( $\operatorname{ceod}=1,79)$ e desvio-padrão ( $\mathrm{dp}=3,09)$ obtidos em um estudo anterior realizado no ano 2000, adotando-se para tal, nível de confiança de $95 \%$, precisão de $20 \%$ e efeito do desenho (deff) de 2. Somaram-se $20 \%$ a esse total, a fim de compensar eventuais perdas e recusas, resultando em um tamanho amostral de 687.

Os sujeitos que fizeram parte deste estudo estavam distribuídos em pré-escolas públicas e privadas do Município de Indaiatuba, sendo para este estudo sorteadas vinte pré-escolas, e finalmente foram selecionadas crianças mediante processo amostral aleatório sistemático.

Os índices utilizados para este levantamento epidemiológico obedeceram aos códigos e critérios recomendados pela OMS 12, com adaptações para atividade de cárie 13. Foram analisadas as seguintes condições: cárie dentária através do índice ceod, necessidades de tratamento e atividade de cárie. A atividade de cárie foi avaliada segundo a reflexão e textura da superfície dentária. Assim, indivíduos com lesões ativas foram considerados aqueles cujas superfícies dentárias apresentaram-se rugosas, opacas e com aspecto de giz. Além desses sinais, foram consideradas a presença de placa bacteriana e/ou gengivite e lesão de cárie aguda (aspecto claro e com descamação) 13 .

Como defeitos de esmaltes foram consideradas as opacidades e hipoplasias, assim considerou-se opacidade demarcada quando o esmalte de um ou mais dentes se apresentaram com a superfície e consistência normais, mas com uma alteração demarcada de translucidez de grau variável, com limites distintos e claros que podem ser brancos creme, amarelo ou marrom. Foi considerado indivíduo com hipoplasia quando o esmalte de um ou mais dentes se apresentaram com perda de estrutura de sua superfície, estando associado a uma diminuição na sua consistência (maior porosidade). O esmalte afetado pode ser translúcido ou opaco 14

O Índice de Cuidados foi aplicado para avaliar os cuidados restauradores a que a população alvo esteve exposta, e é obtido por meio da relação de dentes obturados/ceod x 10015.

A calibração da equipe foi realizada em 36 horas, obtendo porcentagem de concordância interexaminadores de 96\% para cárie, 95\% para as necessidades de tratamento e $60 \%$ para defeitos de esmalte.

Durante os exames a porcentagem de concordância intra-examinadores foi acima de $90 \%$ para cárie e necessidades de tratamento. Estando dessa forma dentro dos limites aceitáveis recomendados por Frias 16.

$\mathrm{Na}$ análise estatística utilizaram-se os testes Mann-Whitney, qui-quadrado e teste de Fisher com nível de significância de 5\%.

Esta pesquisa iniciou-se após a obtenção da aprovação do Comitê de Ética em Pesquisa da Faculdade de Odontologia de Piracicaba (CEP 155/2004).

\section{Resultados}

Foram examinados 624 pré-escolares de cinco anos de idade matriculados em escolas públicas e privadas do Município de Indaiatuba, em 2004. A amostra foi composta de 318 indivíduos do gênero masculino (51\%) e 306 do feminino (49\%). O percentual de perdas da amostra, considerando recusas e ausência na escola das crianças sorteadas no momento dos exames foi aceitável e da ordem de $9,2 \%$. 
Em 2004, 57,4\% $(n=358)$ dos pré-escolares examinados apresentaram-se livres de cáries $(\operatorname{ceod}=0)$, sem diferença segundo o gênero ( $p$ $=0,460)$.

A atividade de cárie, avaliada segundo os critérios de Nyvad et al. ${ }^{13}$, foi verificada em três grupos: em todas as crianças examinadas $(40,5 \%)$, nas crianças com experiência de cárie $(\operatorname{ceod}>0)$ $(91,4 \%)$ e nos escolares sem experiência de cárie $(\operatorname{ceod}=0)(2,8 \%)$, como pode ser visualizado na Figura 1.

A discriminação dos componentes do ceod, em percentual, tanto para os pré-escolares de forma geral quanto segundo o gênero, pode ser visualizada na Figura 2. Segundo o gênero, para nenhum dos componentes foi verificada diferença $(\mathrm{p}>0,05)$.

O histórico da experiência de cárie no $\mathrm{Mu}$ nicípio de Indaiatuba, desde o ano de 1992, expresso por meio do ceod, pode ser visualizado na Figura 3, bem como os componentes do índice.

$\mathrm{O}$ ceod aos cinco anos é apresentado na Figura 4, na mesma figura pode-se ainda verificar a média ceod entre as crianças que apresentaram atividade de cárie, como também entre as crianças com experiência de cárie (ceod $>0$ ). No grupo geral não foi verificada diferença entre ceod e gênero ( $p=0,700)$. Também não foi verificada di- ferença entre os gêneros no grupo com atividade de cárie $(\mathrm{p}=0,258)$ e no com experiência de cárie (ceod $>0$ ), entre os doentes ( $p=0,298$ ).

Analisando-se as necessidades de tratamento nos pré-escolares, segundo o gênero, as meninas apresentaram maior percentual de necessidades restauradoras simples $(p<0,001)$, enquanto os meninos necessitaram de mais restaurações complexas $(\mathrm{p}=0,025)$ e exodontias $(\mathrm{p}=0,049)$, já para a variável indicação de selante não foi verificada diferença quanto ao gênero $(\mathrm{p}=0,328)$, segundo a Figura 5.

Obteve-se a seguir o índice de cuidados, sendo que este foi de 12,3\% aos cinco anos, para os pré-escolares examinados.

Ainda entre os pré-escolares examinados, quanto aos defeitos de esmalte a distribuição foi de $20,7 \%$ com opacidade e de $8,7 \%$ apresentando hipoplasia.

\section{Discussão}

Um elevado percentual de crianças apresentou atividade de cárie (40,5\%), ou seja, presença de manchas brancas ativas (Figura 1), que se não controladas podem progredir para lesões cavitadas. Segundo os critérios da OMS 11 para rea-

Figura 1

Atividade de cárie em todas as crianças, bem como em crianças com (ceod >0) ou sem (ceod = 0) experiência de cárie. Indaiatuba, São Paulo, Brasil, 2004.

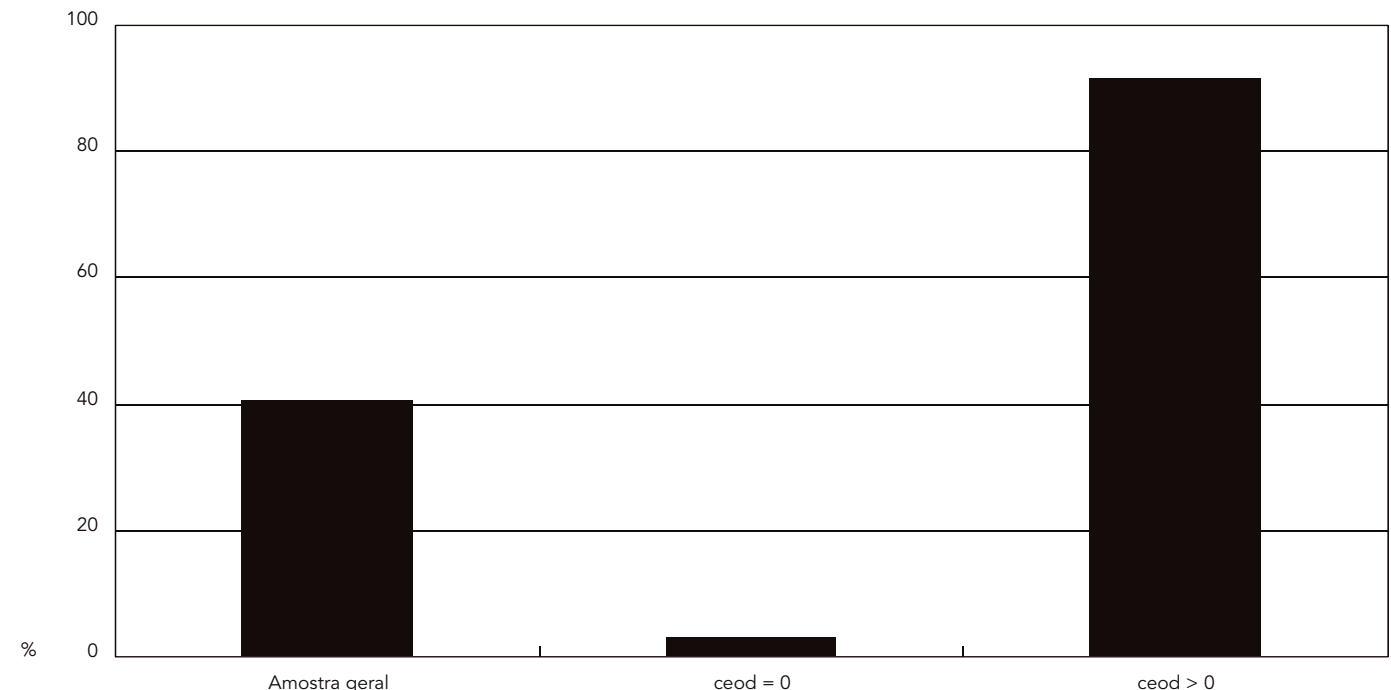


Componentes dos índices ceod aos cinco anos, no grupo geral e segundo o gênero, em percentual. Indaiatuba, São Paulo, Brasil, 2004

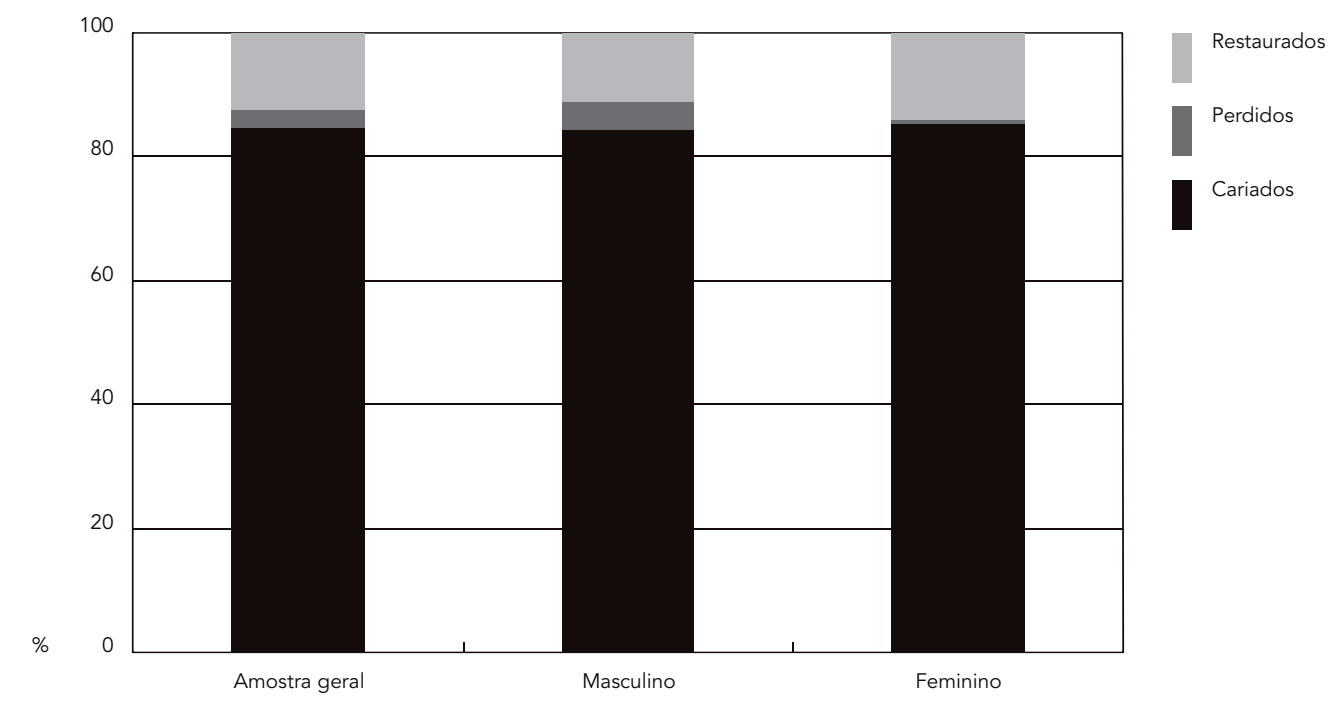

Figura 3

Índice ceod e seus componentes segundo o ano de estudo. Indaiatuba, São Paulo, Brasil, 2004.

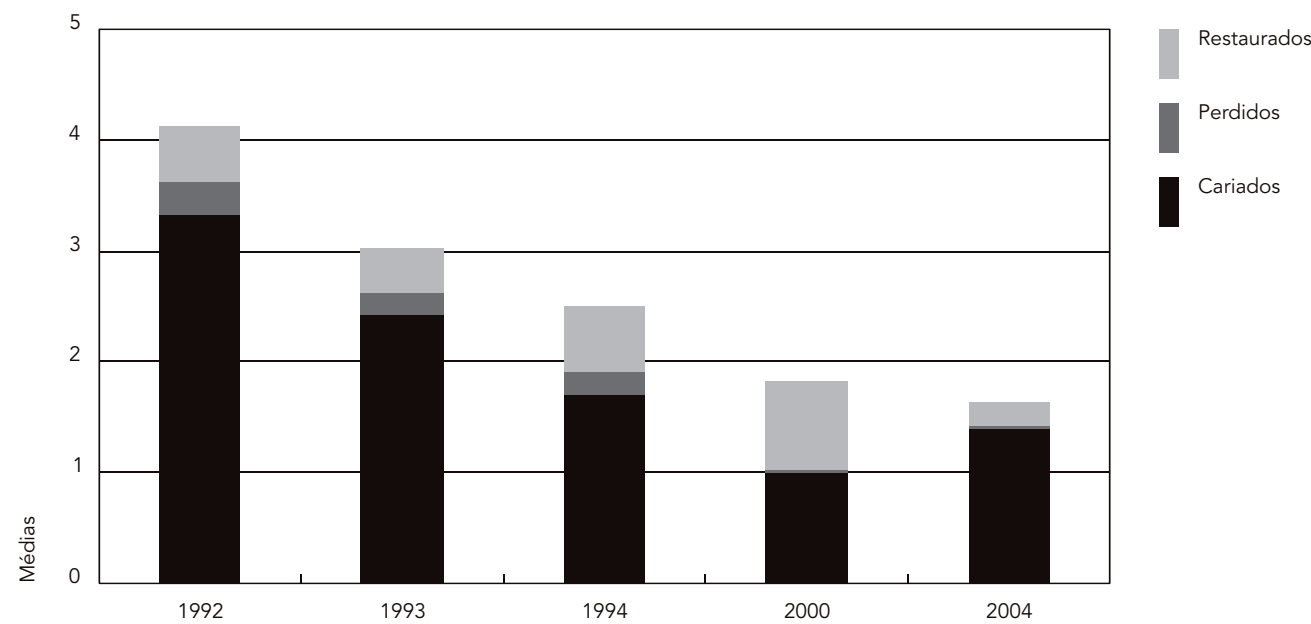


Média ceod no grupo geral, ceod entre as crianças que apresentaram atividade de cárie e ceod entre os doentes (ceod >0). Indaiatuba, São Paulo, Brasil, 2004.

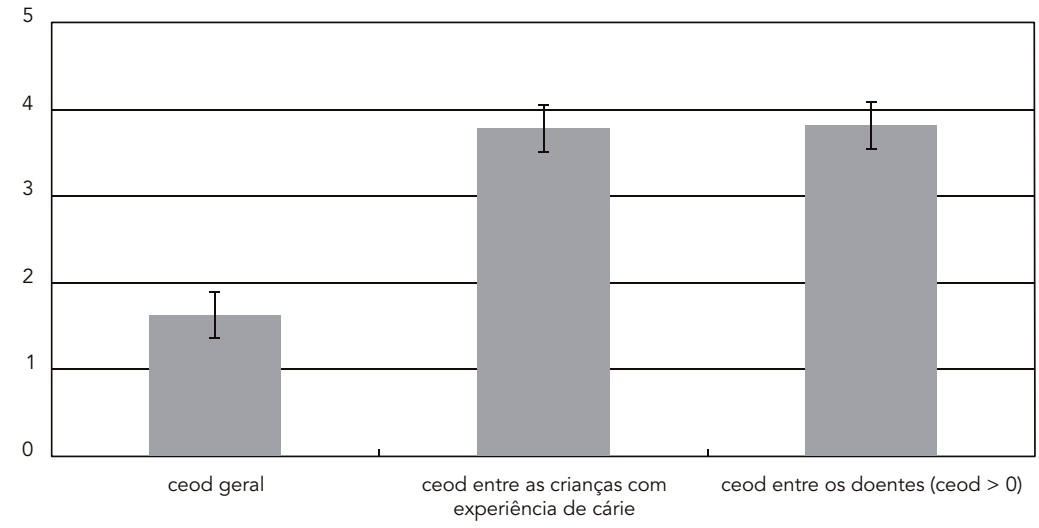

Figura 5

Necessidades de tratamento em pré-escolares segundo gênero. Indaiatuba, São Paulo, Brasil, 2004.

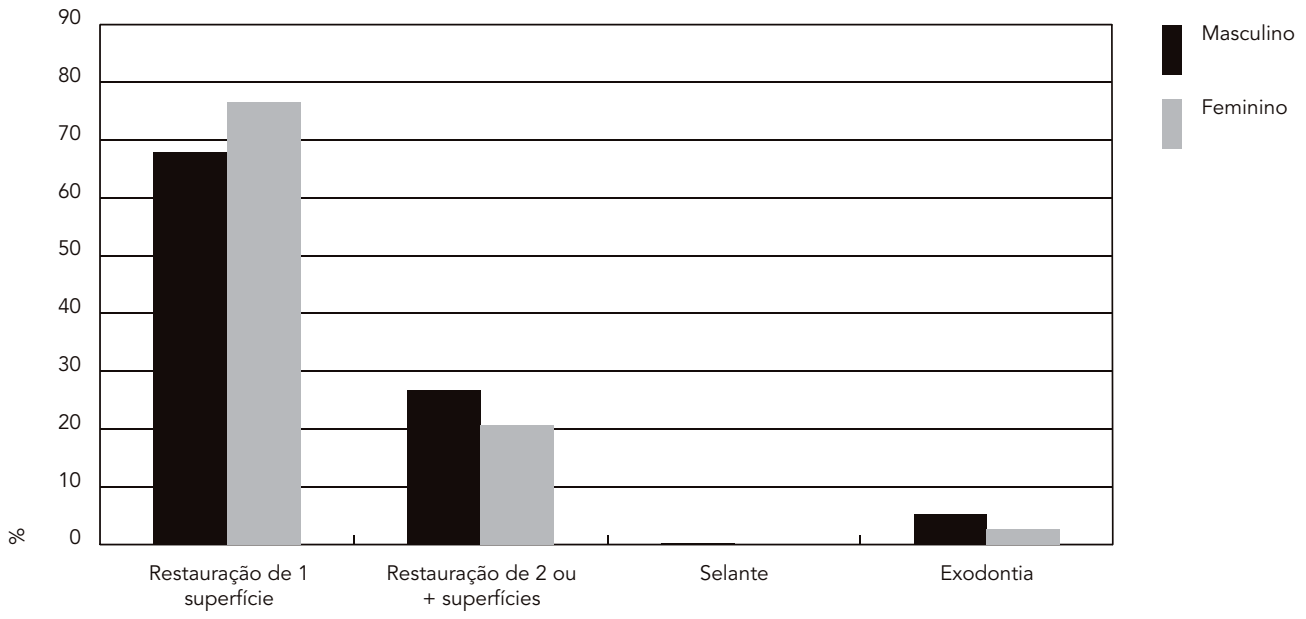

lização de levantamentos epidemiológicos, somente lesões cavitadas são consideradas e assim computadas no cálculo do índice de cárie. Assim, os dentes com lesões de mancha branca ativas, estágio inicial da doença, são considerados como dentes hígidos. Entretanto, uma medida indireta, realizada rotineiramente em levantamentos epi- demiológicos que podem identificar as crianças com atividade de cárie seria na verificação das necessidades de tratamento, onde recomendação de remineralização de esmalte pode contemplar esta questão. A maioria dos trabalhos não relata a presença de manchas brancas ou sinais de atividade. Um fator que pode levar a não inclusão 
dessa variável é a dificuldade de padronização de examinadores para o correto diagnóstico em trabalho de campo, entretanto, medidas como escovação prévia e secagem, além de uma calibração criteriosa podem diminuir este problema. Apesar dessas dificuldades na aferição da atividade de cárie em levantamentos epidemiológicos, ressalta-se a importância da incorporação desta variável em levantamentos epidemiológicos, tendo em vista que a partir deste parâmetro medidas de promoção de saúde, complementadas com medidas como instrução de higiene bucal, aplicação tópica de flúor, aplicação de selantes, entre outras, podem ser incorporadas a esse grupo.

Dentre as crianças que se apresentaram livres de cárie, pequeno percentual apresentou atividade de cárie (que, neste caso, era referente ao estágio inicial da doença - mancha branca ativa), o que pode ser considerado satisfatório, uma vez que mais da metade das crianças eram livres de cárie. Entretanto, quando se estratificou a amostra de acordo com a experiência de cárie (ceod $>0$ ), verificou-se que quase a totalidade desses pré-escolares $(91,4 \%)$ apresentava atividade de cárie, sendo este valor superior ao verificado para o percentual do componente cariado do índice ceod $(84,8 \%)$.

O Município de Indaiatuba possui um histórico de levantamentos epidemiológicos em relação à cárie dentária desde 1992, sendo verificado neste período um declínio na experiência da doença que vem ocorrendo (Figura 3), o que pode ser devido à realização de procedimentos coletivos no município desde 1992, que consistiam de bochechos semanais de flúor a $0,2 \%$, educação em saúde e escovação supervisionada 3 a 4 vezes ao ano, além do município possuir água de abastecimento público fluoretada, com cerca de $70 \%$ das amostras analisadas pelo Programa PróÁgua oscilando entre 0,6 a 0,8ppm de flúor 17 .

Tem sido verificada uma grande variação na prevalência da cárie dentária em várias localidades, 4,7,18,19 sendo que nível sócio-econômico e fatores culturais interferem no desenvolvimento de cáries 19,20,21. Locais considerados como de primeiro mundo apresentam valores de ceod mais baixos, como Reino Unido $22(1,52)$, Inglaterra $6(1,49)$, entretanto, outras localidades apresentam ceod elevado 5,6,7,8. Considerando-se o fator sócio-econômico, verifica-se que, mesmo em países considerados desenvolvidos, observase que crianças cujas famílias possuem menor renda apresentam mais cáries que as de famílias mais favorecidas. Dessa forma, buscou-se comparar Indaiatuba com outras localidades próximas ao município, dentro do mesmo Estado, que apresentavam condições sócio-econômicas semelhantes a Indaiatuba, medidas por meio do
IDH, apresentando valores acima de 0,80 (alto desenvolvimento humano) 11 , verificou-se que Indaiatuba apresentou valor de ceod inferior à região de Sorocaba $7(3,1)$, Rio Claro $23(2,48)$, podendo ser equiparada à encontrada em Paulínia $24(1,9)$, sendo que este município do Estado de São Paulo possui ainda como particularidade apresentar há muitos anos histórico de atenção à saúde bucal, inclusive ao pré-escolar.

Considerando-se os componentes do índice ceod, verificou-se que grande parte do índice era composto pelo componente cariado (Figura 2), assim como em outros estudos, tanto em localidades próximas a do estudo 7,25,26 quanto internacionalmente 6 . Esses dados revelam a necessidade de uma maior cobertura dos serviços odontológicos, pois o índice de cuidados não atinge $15 \%$ das necessidades restauradoras, ou seja, apenas este percentual de dentes estão tratados, sendo que o restante representa cáries não tratadas ou dentes perdidos. Comparando com outras localidades, o índice de cuidados em Indaiatuba apresenta-se abaixo do encontrado em Leme 26 (25,5\%), Reino Unido 22 (13,2\%), e em Paulínia 24 (65,4\%), aos cinco anos de idade.

O sexo feminino apresentou maiores necessidades de tratamentos restauradores simples (restauração de uma superfície), enquanto o sexo masculino apresentou maiores necessidades restauradoras complexas e de exodontias (Figura 5). Uma vez que através do índice ceod não foram verificadas diferenças quanto ao gênero, esse achado pode sugerir indiretamente que os meninos tenham apresentado piores condições bucais ou que procurem por tratamento de forma mais tardia.

Quando os indivíduos livres de cárie foram excluídos da amostra, o ceod entre os doentes (42,6\% da população) foi de 3,81 (Figura 4), valor bem diferente de ceod igual a 1,73 que foi a média geral nessa população de pré-escolares, sugerindo-se, desta forma, cuidado na avaliação de dados epidemiológicos, recomendando-se assim a utilização de outras medidas além do índice ceod que explorem melhor a condição de saúde bucal na população com experiência da doença, como por exemplo, a atividade de cárie.

Verificou-se nessa população que a média de ceod dentre os doentes e a média do ceod dentre os que apresentaram sinais de atividade de cárie (Figura 4) foi muito próxima, caracterizando o índice ceod como bom indicador de atividade nesses grupos, mesmo neste município que apresentou, em média, valor de ceod baixo, isto talvez porque o componente cariado do índice prevaleça nessa população. Ressalta-se que não houve nenhuma indicação de remineralização de manchas brancas neste estudo, apesar de se 
verificar elevado percentual de crianças com atividade de cárie.

Em relação à prevalência de opacidades (20,7\%) e hipoplasias (8,7\%), o Município de Indaiatuba pela primeira vez verificou sua ocorrência, que, segundo Gomes et al. ${ }^{24}$, esta condição tende a ser enfatizada em levantamentos epidemiológicos, pois tem sido considerada como um fator de risco para cárie dentária 27 . Li et al. 28 consideraram em seu trabalho as hipoplasias de esmalte como mais forte preditor de cárie que renda familiar ou país de residência, o que ressalta a importância do estudo desta condição.

\section{Resumo}

Os objetivos deste trabalho foram verificar a atividade de cárie, além de conhecer a experiência de cárie (ceod), necessidades de tratamento e defeitos de esmalte em pré-escolares de cinco anos de idade. Examinaram-se 624 crianças de Indaiatuba, São Paulo, Brasil, em 2004, selecionadas por meio de processo amostral aleatório sistemático. Para medir a experiência de cárie e necessidade de tratamento adotou-se os critérios da OMS. Para a atividade de cárie, optou-se por uma simplificação dos critérios de diagnóstico de Nyvad et al. Na análise estatística utilizaram-se os testes Mann Whitney e qui-quadrado com nivel de significância de 5\%. 40,5\% dos pré-escolares apresentaram atividade de cárie. O ceod foi de 1,62 (IC95\%: 1,35-1,89). Entre os doentes (ceod >0) o ceod foi 3,81 (IC95\%: 3,36-4,26), ainda neste grupo, 91,4\% das crianças apresentaram atividade de cárie. O índice de cuidados foi de 12,3\%. Sugere-se que medidas de prevenção e tratamento direcionadas a essa população continuem sendo priorizadas, uma vez que as medidas de controle e paralisação da cárie em seus estágios iniciais são bem conhecidas. Além disso, recomenda-se cuidado direcionado aos pré-escolares com maior experiência de cáries.

Cárie Dentária; Fluorose Dentária; Saúde Bucal; PréEscolar

\section{Conclusões}

Indaiatuba apresenta baixa prevalência de cárie aos cinco anos, tendo atingido as metas da OMS para o ano 2000, entretanto, recomenda-se que os esforços sejam direcionados visando à paralisação ou controle das lesões iniciais de cárie no grupo com atividade da doença. Além disso, sugere-se intensificação do atendimento curativo nas crianças que possuem experiência de cárie (ceod $>0$ ), além do monitoramento das opacidades e hipoplasias no município.

\section{Colaboradores}

M. L. R. Sousa e S. Cypriano contribuíram na calibração da equipe de examinadores. N. M. Abdalla participou do planejamento regional do estudo. D. D. N. Guidini e C. Amgarten foram responsáveis pela coleta de dados no município. L. B. Rihs organizou o banco de dados e realizou a análise estatística. L. B. Rihs, M. L. R. Sousa e S. Cypriano realizaram em conjunto todas as demais etapas do trabalho, desde a análise dos resultados até a redação do artigo científico.

\section{Agradecimentos}

Às crianças e seus responsáveis por autorizarem que os exames epidemiológicos fossem realizados.

Ao coordenador de saúde bucal de Indaiatuba em 2004, Ricardo José Gonçalves Silva responsável pela coleta dos dados, e à coordenadora de saúde bucal em 2005, Maria Luisa Carramenha e Costa Faber pela disponibilização dos dados. 


\section{Referências}

1. Creedon MI, O'Mullane DM. Factors affecting caries levels amongst 5-year-old children in Country Kerry, Ireland. Community Dent Health 2001; 18:72-8.

2. Li Y, Wang W. Predicting caries in permanent teeth from caries in primary teeth: an eight-year cohort study. J Dent Res 2002; 81:561-6.

3. Skeie MS, Raadal M, Strand GV, Espelid I. The relationship between caries in the primary dentition at 5 years of age and permanent dentition at 10 years of age - a longitudinal study. Int J Paediatr Dent 2006; 16:152-60.

4. Lucas SD, Portela MC, Mendonça LL. Variações no nível de cárie dentária entre crianças de 5 e 12 anos em Minas Gerais, Brasil. Cad Saúde Pública 2005; 21:55-63.

5. Downer M. Caries prevalence in the United Kingdom. Int Dent J 1994; 44:365-70.

6. Pitts NB, Boyles J, Nugent ZJ, Thomas N, Pine CM. The dental caries experience of 5 -years-old children in England and Wales (2003/4) and Scotland (2002/3). Community Dent Health 2005; 22:46-56.

7. Cypriano S, Pecharki GD, Sousa MLR, Wada RS. A saúde bucal de escolares residentes em locais com ou sem fluoretação nas águas de abastecimento público na Região de Sorocaba, São Paulo, Brasil. Cad Saúde Pública 2003; 19:1063-71.

8. Hashim R, Thomson WM, Ayres KM, Lewsey JD, Awad M. Dental caries experience and use of dental services among preschool children in Ajman, UAE. Int J Paediatr Dent 2006; 16:257-62.

9. Couto GBL, Vasconcelos MMVB, Melo MMC, Camelo CAC, Valença PAM. Prevalência de cárie, mancha branca e placa visível em crianças de 0 a 36 meses, assistidas pelo Programa de Saúde da Família na Cidade de Camaragibe - PE. Odontol Clín-Cient 2005; 4:19-28.

10. Pinto VG. Programação em saúde bucal. In: Pinto VG, organizador. Saúde bucal coletiva. São Paulo: Santos; 2000. p. 139-222.

11. Fundação Sistema Estadual de Análise de Dados. Perfil municipal. http://www.seade.gov. br/produtos/perfil/perfil.php (acessado em 07/ Jun/2006).

12. Word Health Organization. Oral health surveys, basics methods. Geneva: Word Health Organization; 1997.

13. Nyvad B, Machiulskiene V, Baelum V. Reliability of a new caries diagnostic system differentiating between active and inactive caries lesions. Caries Res 1999; 33:252-60

14. Secretaria do Estado da Saúde de São Paulo/Universidade Estadual de Campinas. Condições de saúde bucal, 2004 - caderno de instruções. Campinas: Direção Regional de Saúde de Campinas, Secretaria de Estado da Saúde de São Paulo; 2004.
15. Walsh J. international patterns of oral health care - the example of New Zealand. N Z Dent J 1970; 66:143-52.

16. Frias AC. Estudo de confiabilidade do levantamento epidemiológico de saúde bucal - Estado de São Paulo, 1998 [Dissertação de Mestrado]. São Paulo: Faculdade de Saúde Pública, Universidade de São Paulo; 2000.

17. Secretaria de Estado da Saúde de São Paulo. Avaliação da atenção básica. http://www4.saude.sp.gov. br/indicadores/indicadores.asp (acessado em 30/ Ago/2005).

18. Leite IC, Ribeiro RA. Dental caries in the primary dentition in public nursery school children in Juiz de Fora, Minas Gerais, Brazil. Cad Saúde Pública $2000 ; 16: 717-22$.

19. Marthaler TM. Changes in dental caries 1953-2003. Caries Res 2004; 38:173-81.

20. Antunes JL, Frazão P, Narvai PC, Bispo CM, Pegoretti T. Spatial analysis to identify differentials in dental needs by area-based measures. Community Dent Oral Epidemiol 2002; 30:133-42.

21. Tinanoff N, Kanellis MJ, Vargas CM. Current understanding of the epidemiology mechanisms, and prevention of dental caries in preschool children. Pediatr Dent 2002; 24:543-51.

22. Pitts NB, Boyles J, Nugent ZJ, Thomas N, Pine CM. The dental caries experience of 5-years-old children in England e Wales. Community Dent Health 2003; 20:45-54.

23. Hoffmann RHS, Cypriano S, Sousa MLR, Wada RS. Experiência de cárie dentária em crianças de escolas públicas e privadas de um município com água fluoretada. Cad Saúde Pública 2004; 20:522-8.

24. Gomes PR, Costa SC, Cypriano S, Sousa MLR. Paulínia, São Paulo, Brasil: situação da cárie dentária com relação às metas OMS 2000 e 2010. Cad Saúde Pública 2004; 20:866-70.

25. Secretaria de Estado da Saúde de São Paulo/Universidade de São Paulo. Condições de saúde bucal no Estado de São Paulo em 2002. São Paulo: Centro Técnico de Saúde Bucal, Secretaria de Estado da Saúde de São Paulo; 2002.

26. Rihs LB, Tagliaferro EPS, Sousa MLR, Martins J, Hildebrand LF, Felizatti RC. Prevalência de cárie e fluorose dentária em pré-escolares de 5 e 6 anos, Leme, SP, 1998. RFO UPF 2003; 8:34-9.

27. Seow WK. Enamel hypoplasia in the primary dentition: a review. ASDC J Dent Child 1991; 58:441-52.

28. Li Y, Navia JM, Bian JY. Caries experience in deciduous dentition of rural Chinese children 3-5 year old in relation to the presence or absence of enamel hypoplasias. Caries Res 1996; 30:8-15.

Recebido em 14/Out/2005

Versão final reapresentada em 05/Jul/2006 Aprovado em 26/Jul/2006 